\title{
Herbivory and Plant Genotype Influence Fitness-Related Responses of Arabidopsis thaliana to Indirect Plant-Plant Interactions
}

\author{
Jennifer Shimola, M. Gabriela Bidart* \\ Department of Biological Sciences, Bowling Green State University, Bowling Green, USA \\ Email: *gbidart@bgsu.edu
}

How to cite this paper: Shimola, J. and Bidart, M.G. (2019) Herbivory and Plant Genotype Influence Fitness-Related Responses of Arabidopsis thaliana to Indirect Plant-Plant Interactions. American Journal of Plant Sciences, 10, 1287-1299. https://doi.org/10.4236/ajps.2019.108093

Received: July 2, 2019

Accepted: August 18, 2019

Published: August 21, 2019

Copyright $\odot 2019$ by author(s) and Scientific Research Publishing Inc. This work is licensed under the Creative Commons Attribution International License (CC BY 4.0).

http://creativecommons.org/licenses/by/4.0/

\section{(c) (i) Open Access}

\begin{abstract}
Previous studies have demonstrated that genetic identity between interacting perennial plants results in more effective defense when emitter and receiver neighbors have greater genetic similarity. However, the effects of both genetic relatedness and presence of herbivores on fitness-related responses of neighboring plants have not yet been explored. Our aim was to examine how manipulating these two important factors genetic and environmental factors can influence indirect plant-plant communication in the annual crucifer Arabidopsis thaliana. Plants of a single genotype (receivers) were exposed to volatile emissions of neighboring emitter plants with a similar or different genotype, and either intact or damaged by larvae of a specialist herbivore for ten days. Each of the four treatments was isolated in separate environmental chambers and the full experiment was replicated twice. Receiver plant growth and reproductive-related traits were measured ten days after exposure to treatments, and at senescence. Results showed that the effect of herbivory and plant genotype of emitter plants influenced responses related growth and reproduction in receiver plants. Receiver plants grew taller, had more inflorescence branching, and produced more fruits $(60 \%$ more) when exposed to undamaged emitters of a different genotype than receivers exposed to the other emitter plant treatments. Therefore, genotype identity and environmental context (presence of herbivory) may be important factors influencing indirect plant-plant communication, which could, in turn, result in selection for genotypes showing increased fitness-related responses.
\end{abstract}

\section{Keywords}

Plant-Plant Interactions, Plant Genotype, Insect Herbivory, Fitness-Related Responses 


\section{Introduction}

Due to their inability to escape stressful environments, plants have evolved mechanisms to physiologically deter herbivores and competitors through chemical and mechanical defenses, or by enhanced growth to compensate for tissue loss. Plant defenses can be expressed constitutively or inducibly to reduce fitness costs [1] [2] [3]. Induction is a process under which plants increase physical and chemical defenses after they have incurred damage from environmental stressors such as pathogens, or herbivores. Plant inducible defense mechanisms are metabolically advantageous due to reductions in production costs when herbivory does not occur [4]. To further fine-tune induction responses to antagonists, such as herbivores, plants can communicate via airborne volatiles [5] [6]. Plant exposed to volatile cues have been shown to reduce subsequent herbivore damage in Artemisia tridentata [7] [8], or to increase competitive ability in Nicotiana tabacum [9] [10].

Even though plant volatile cues can travel through space rapidly [11], the efficiency for which volatile cues can be received seem to depend on emitter-receiver identity. In the perennial shrub, Artemisia tridentata, plant-plant communication was more effective in reducing herbivory when plants were exposed to volatiles of neighbors with greater genetic similarity [12] [13] than those exposed to volatiles of genetically distinct neighbors. The effect of plant genetic identity on induced responses has been attributed to a similarity in volatile cues between close relatives [14]. As such, plants that interact with neighbors with a similar volatile bouquet may be able to gather information about the environment more effectively than plants exposed to genetically distinct neighbors. However, more information is needed regarding potential effects of plant genotype relatedness on plant-plant communication mediated by airborne volatile cues.

Differences in the genetic identity of emitter and receiver plants may influence plant characters related to structure or architecture (e.g., vascular systems, branching, aboveground tissue and roots, etc.). Plant structure has been shown to affect how chemical cues are transmitted within a plant due to the variable connectivity of the vascular transport system for different phyllotaxies [15]. Many species display these vascular signaling constraints, which results in uneven signal transduction [16] [17] [18]. Airborne defense signaling is thought to circumvent these structural constraints [15] [19]. However, not all species are limited by within plant signaling due to phyllotaxy [20] [21]. Therefore, airborne defense signaling may be influenced by the efficiency of plant internal transport systems of defense chemicals involved in plant-plant communication [15].

Plant-plant communication can also be important for integrative pest management, since induced neighbouring plants may show higher resistance against insect pest attacks [14]. These responses have been shown not only in wild plant species, including Arabidopsis thaliana, but also in some agriculturally important plant species. Current research has demonstrated that some domesticated 
crops have retained that ability to communicate via volatiles, which shows potential for the development of strains that could maximize the benefit of plant-plant communication through selective breeding [22] [23] [24] [25]. In addition, resource costs of plant-plant priming via airborne volatiles should be lower than herbivore-induced defenses, which may allow plants to allocate more energy to growth and enhanced yields [5] [6]. These ideas are relatively new, and more studies are needed to test the potential value of incorporating plant-plant communication as a pest management strategy.

Current research on plant-plant communication has focused on either how plants of different species interact [22] or how perennial species interact with conspecifics [12] [13] [26]. This study was aimed at determining whether plant genotype and herbivory in emitter plants influenced fitness-related responses of receiver plants. We hypothesized that receiver plants may differ in responses related to growth and reproduction when exposed to plant volatiles from emitters with the same or distinct genetic background, and that these responses may also be influenced by the presence or absence of herbivores. Genetic similarity in volatile profiles could provide a potential mechanism for plants to distinguish neighbors, and to differentially respond to insect herbivory. The model plant, Arabidopsis thaliana, provides an ideal system for this research due to its short generation time, and the presence of genetically distinct lines differing in their volatile chemical signatures [27] [28].

\section{Materials and Methods}

\subsection{Study Organism and Growing Conditions}

Two wild-type lines of Arabidopsis thaliana, Columbia (Col-0) and Landsberg erecta (Ler), were used to evaluate the effect of genotype and herbivore damage (present or absent) of emitter plants on fitness-related traits of neighboring receiver plants. The selected genotypes are known to differ in their volatile chemical composition, but have similar developmental and growth-related characters [27] [28]. Ler genotype plants have been demonstrated to constitutively produce less (Z)- $\beta$-ocimene [28], but more hexanal [27] than Col-0 genotype plants. Ler plants also produce trans-2-hexenal, which is absent in Col-0 volatile emissions [27]. Emitter plants of both genotypes were grown from seed obtained from the Arabidopsis Biological Resource Center (Columbus, $\mathrm{OH}$ ) in 10-cm pots (volume: $511 \mathrm{~cm}^{3}$ ) filled with a commercial soil mix, Metromix Pro-Mix BX (Premier Tech Horticulture, Quakertown, PA). Emitter plants were started two weeks prior to planting receiver plants to ensure a sufficient source of food for larvae during pre-treatments. Receiver plants were planted in 5-cm pots (volume: 98 $\mathrm{cm}^{3}$ ) filled with Turface All Sport (Profile Products LLC, Buffalo Grove, IL), which facilitates root harvest. Due to the lack of organic matter in this media, all receiver plants were supplemented with a balanced, 14-14-14, slow-release fertilizer (The Scotts Company, Marysville, $\mathrm{OH}$ ), at a rate of $0.9 \mathrm{~kg} \cdot \mathrm{m}^{-3}$ when first planted; and further supplemented with liquid 20-20-20 fertilizer (JR Peters Inc, 
Allentown, PA) at a rate of $0.82 \mathrm{~g} \cdot \mathrm{L}^{-1}(166 \mathrm{ppm} \mathrm{N})$ when watered weekly. Upon planting, both emitter and receiver plant seeds were cold-treated at $4^{\circ} \mathrm{C}$ under dark conditions for five days to break dormancy and ensure uniform germination. After the cold treatment, emitter and receiver planted seeds (in pots) were transferred to growth chambers set to 14:10 hour day-night cycle and at a temperature of $21^{\circ} \mathrm{C}$.

\subsection{Experimental Design}

Receiver plants of the Col-0 genotype were exposed to emitter plants assigned to four treatments: 1) intact emitters with the same genetic background (i.e., Col-0), 2) herbivore-damaged emitters with the same genetic background (i.e., Col-0), 3) intact emitters with a different genetic background (i.e., Ler), or 4) herbivore-damaged emitters with a different genetic background (i.e., Ler). A set of eight receiver plants was arranged equidistantly around two emitter plants (three sets per chamber and per experimental repetition). All emitter plants (both intact and herbivore-damaged) were covered with a plastic container covered in fine mesh to confine insect larvae, when present. To avoid pseudoreplication, due to treatments being confounded with chambers (one treatment per chamber), the entire experiment was replicated in time (two experimental rounds) with treatments randomly assigned to growth chambers in each repetition.

Treatments were performed in four separate, sealed growth chambers (Percival Scientific model AR36L3C8, Perry, IA, USA) to eliminate potential volatile contamination between genotype and herbivore-damaged treatments. Special care was taken to minimize plant exposure to volatiles from another treatment/chamber by allowing 80 minutes of ventilation time between accessing different chambers. Ventilation time was determined via an equation of ventilation [29], which estimates when the final concentration of plant volatiles would reach zero to indicate no further volatile pollution in the room. Turnover of total air in the room was determined by using the environmental chamber room's volume (space volume), the concentration of volatiles (environmental chamber volume), and the time until total air turnover (ventilation rate). The initial concentration of plant volatiles considered the total volume of the environmental chambers divided by the enclosed room volume. The minimum exhaust rate of the room's ventilation system was used as ventilation rate.

Three second-instar larvae of the crucifer specialist Plutella xylostella L. (Lepidoptera: Plutellidae) were placed on each herbivore-damaged emitter for ten days. The herbivore treatment was started on emitter plants when they were four weeks old. Moth larvae originated from a lab culture (Benzon's Research; Carlisle, Pennsylvania, USA), which had been raised on an artificial diet prior to this experimental setup. Receiver plants were exposed to emitter plants of the 4 different treatments for 10 days. After these 10-days, emitter plants were removed from all chambers. Receiver plants were only exposed to the volatile cues of adjacent damaged or undamaged emitter plants. They were not exposed to direct 
herbivore damage and they were never in direct contact with emitter plants.

\subsection{Plant Fitness-Related Responses}

Plant diameter of receiver plants was recorded at the beginning of the experiment, and after the ten-day exposure to the different emitter treatments. The change in diameter of receiver plants before and after those ten days was used in the statistical analyses. At senescence, the following traits were measured: 1) plant height was measured from the base of the plant rosette to the longest stem, 2) fruit number was recorded by counting the total number of fruit pods per plant, 3) branch number included the total number of lateral branches per plant, and 4) above-ground and total biomass were measured. To determine biomass for aboveground (leaves and stems) and total biomass (including roots), plant material was oven-dried $\left(80^{\circ} \mathrm{C}\right)$ for five days and weighed. In addition, to determine whether receiver plants were allocating resources in different proportions to shoots and roots, above-ground biomass was divided by total biomass.

\subsection{Statistical Analysis}

A mixed model analysis of variance was performed to test for the fixed effects of genotype, herbivory treatment, the interaction of genotype and herbivory, and the random effect of experimental repetition (two rounds) on plant height, fruit number, branch number, change in rosette diameter, and the ratio of aboveground to total biomass. When assumptions of normality and heterogeneity were not met, data were transformed using a logarithmic or square root transformation. Pairwise comparisons among treatment means were performed using Fisher's Least Significant Difference tests when ANOVA models were significant (protected LSD). Statistical analyses were performed using SAS version 9.3 (SAS Institute, Cary, NC, USA).

\section{Results}

Results from analyses of variance indicated that emitter plant treatments (i.e., genotype identity and herbivore damage) significantly affected several receiver plant-fitness related traits (Table 1). There was also a significant effect of the repetition of the experiment on branch number, fruit set, and biomass of receiver plants; however, results showed similar trends between the experimental repetitions (Table 1 and Figure 1). Genotype identity of emitter plants significantly influenced plant rosette diameter, height, number of branches, total biomass, and fruit number of receiver plants (Table 1). Likewise, the effect of herbivore damage on emitter plants, and the interaction of damage and genotype significantly influenced height, branch number, total biomass, and fruit set of receiver plants (Table 1). As indicated by the significant genotype by damage interaction, these two factors modified plant receiver responses to emitters. Results from Fisher's LSD post-hoc multiple comparisons showed that receiver plants had significantly larger growth (increase diameter, height, total biomass, and fruit 
Table 1. Mixed-model ANOVA evaluating effects of emitter genotype (Col-0 or Ler) and herbivore treatment of emitters (undamaged or damaged) on receiver $A$. thaliana fitness-related traits: change $(\Delta)$ in rosette diameter before and after treatment exposure, final height and total biomass, the ratio of above-ground (ABG) to total biomass, and total branch and fruit number. Experimental repetition was included in the analyses as a random effect. Significant $F$-values are shown in boldface $(P<0.05) . d f=$ degrees of freedom.

\begin{tabular}{cccccc}
\hline & \multicolumn{4}{c}{ ANOVA source of variation $(F$-values $)$} \\
\hline Treatment & $d f$ & Genotype & Damage & Gen $\times$ Dam & Repetition \\
\hline$\Delta$ Diameter & 4,143 & $\mathbf{9 . 0 5}$ & 0.01 & 3.15 & 2.3 \\
Height & 4,130 & $\mathbf{3 1 . 2 2}$ & $\mathbf{1 4 . 8 9}$ & $\mathbf{1 5 . 8 9}$ & 3.74 \\
Total Biomass & 4,130 & $\mathbf{7 . 4 8}$ & $\mathbf{1 5 . 7 1}$ & $\mathbf{2 2 . 5 1}$ & 0.01 \\
ABG/Total Biomass & 4,130 & 0.09 & 0.54 & $\mathbf{4 . 5 6}$ & $\mathbf{2 . 9 7}$ \\
Branch Number & 4,130 & $\mathbf{8 . 4 9}$ & $\mathbf{5 . 0 4}$ & $\mathbf{1 6 . 4 2}$ & $\mathbf{1 1 . 3 6}$ \\
Fruit Number & 4,130 & $\mathbf{1 0 . 3 1}$ & $\mathbf{2 3 . 5 2}$ & $\mathbf{2 3 . 5 2}$ & $\mathbf{1 2 . 6 2}$ \\
\hline
\end{tabular}

number) when exposed to emitters of a different genotype (Ler) compared to emitters of the same genotype (Col-0), although only when Ler was not exposed to herbivory (Figure 1). The presence of herbivores on Ler emitters cancelled this enhanced growth response in receiver plants. On average, receiver plants exposed to undamaged Ler emitters grew 14\% taller (Figure 1(b)), weighed 32\% more (Figure $1(\mathrm{c})$ ), produced $42 \%$ more branches (Figure $1(\mathrm{e})$ ) and $62 \%$ more fruits (Figure 1(f)) than receiver plants exposed to all other emitter treatments. However, the first experimental round had 22\% more branches, $21 \%$ more biomass allocated aboveground, and $24 \%$ more fruits compared to the second one, but the trend direction was similar between rounds (Figure 1). Despite a significant overall increase in total biomass and other plant-fitness related traits, the proportion of above-ground biomass from the total biomass did not differ among receiver plants exposed to the different emitter plant treatments (Figure $1(\mathrm{~d})$ ). In other words, emitter plant treatments did not affect the allocation of resources to above- and below-ground biomass.

\section{Discussion}

This study showed that plant genotype relatedness and the presence or absence of herbivores on emitters had a significant effect on fitness-related traits of receiver plants. We hypothesized that receiver plants might differ in responses to both the genetic identity and herbivore damage status (damaged or intact) of emitter plants, but only undamaged emitters of a different genetic background (Ler) induced a change in the phenotype of receivers. This change involved an increase in plant stem height, number of branches, total biomass, and fruit set. A previous similar study measured resource allocation in barley (Hordeum vulgare) plants exposed to volatiles of intact emitters from the same and a different cultivar [23]. No overall increase in biomass for plants exposed to emitters of either barley cultivar was observed [23]. However, consistent with our findings, 


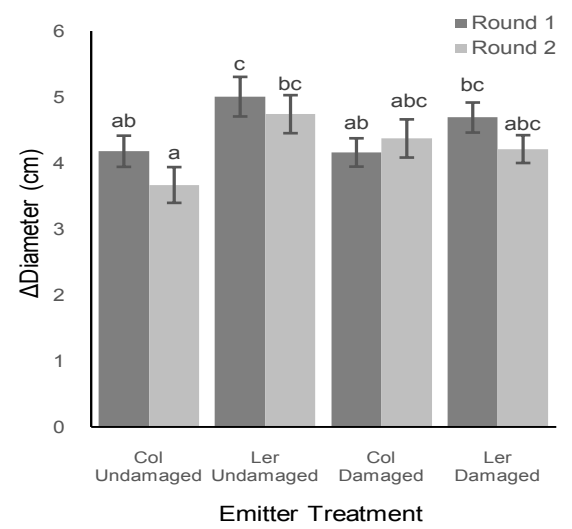

(a)

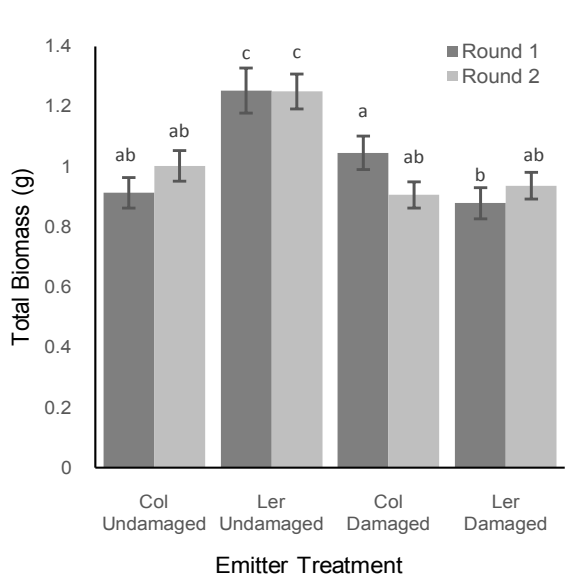

(c)

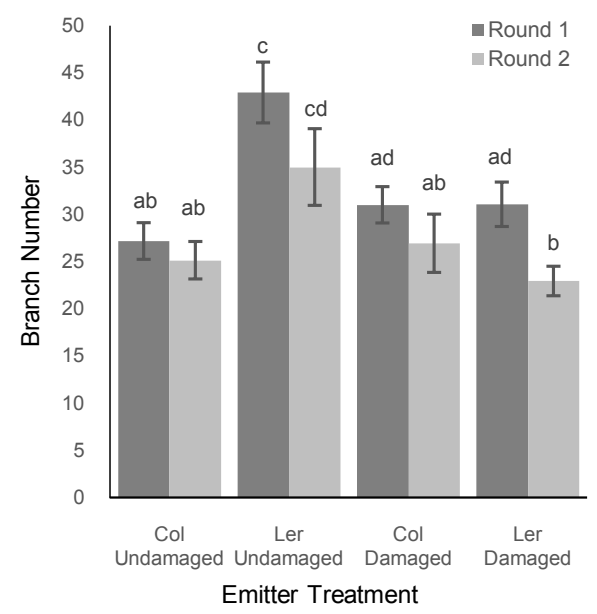

(e)

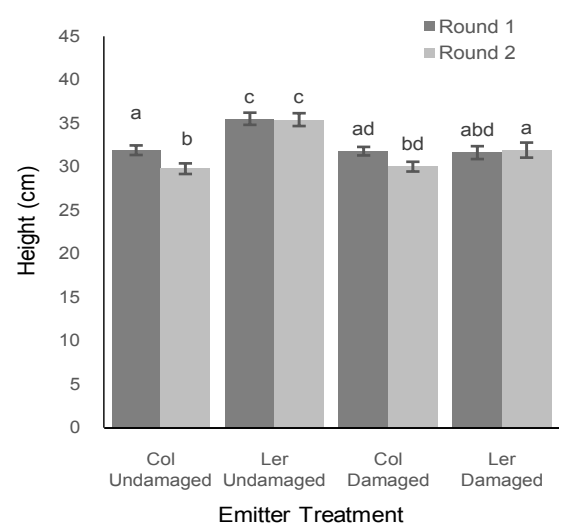

(b)

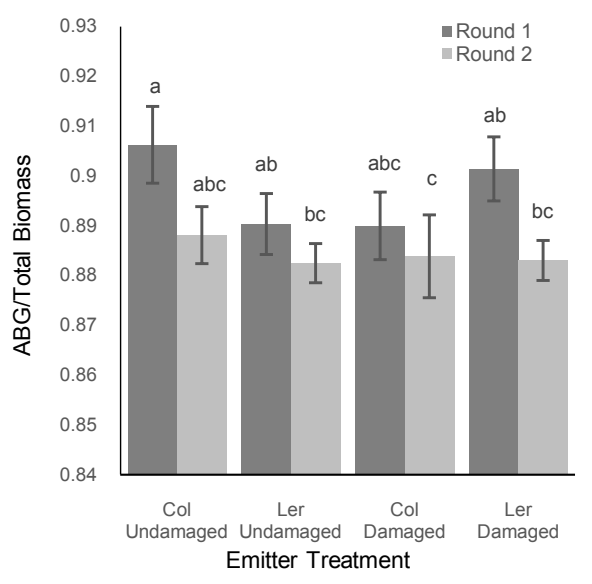

(d)

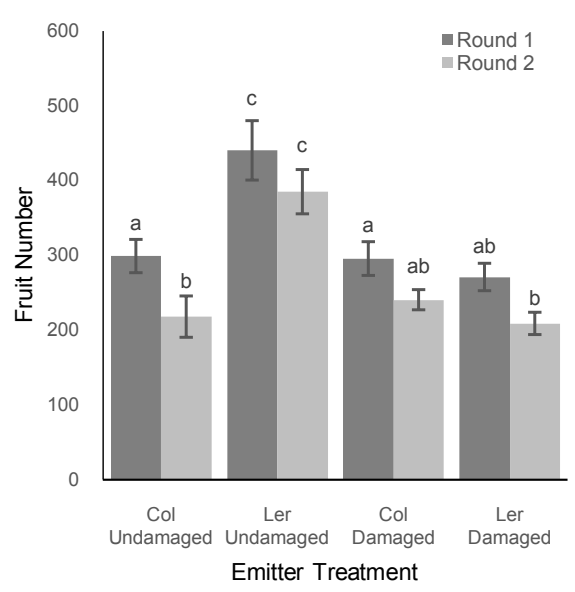

(f)

Figure 1. Effects of emitter genotype (Col-0 or Ler) and herbivore treatment of emitters (undamaged or damaged) on receiver $A$. thaliana fitness-related traits (means and standard errors): (a) change $(\Delta)$ in plant diameter after exposure to emitter treatments, (b) inflorescence height, (c) total dry plant biomass (in grams), (d) ratio of dry plant biomass allocated above-ground (ABG) to total biomass, (e) inflorescence branch number, and (f) fruit set. Different letters above bars represent significant differences between treatment means based on Fisher's LSD post-hoc multiple comparisons $(P<0.05)$. "Round" numbers represent results from each repetition of the full experiment. 
specific leaf area increased in barley exposed to the volatiles of a different cultivar in the absence of herbivores [23].

While studies on the effect of neighbor identity through volatile cues are uncommon, the observed elongated phenotypes of receiver plants could be considered analogous to shade avoidance or competitive phenotypes. Changes in plant structure such as elongated height are characteristic responses to the presence of competitors [24] [30] [31] [32], and $A$. thaliana has been shown to express petiole elongation and increased canopy height in response to competition [33]. Increasing the height of photosynthetic surfaces and root branching promote competitive ability, ultimately allowing plants to gather more resources such as sunlight aboveground, and water or nutrients belowground [34] [35]. Even though competition was not manipulated in our study (as plants were not allowed to directly interact with neighbors), the observed increase in growth-related traits of receiver plants of a different genotype than emitter plants resembled a plant-plant competition-like response. Since volatile composition differs between the genotypes selected for this study [27] [28], it could be speculated that receiver plants could "recognize" a genetically distinct neighbor through airborne volatiles. This could, in turn, elicit receiver phenotypes to mount a response to a potential stressor such as competition. It has been previously demonstrated that airborne chemical cues can activate shade avoidance responses, and thus, facilitate competitive preparedness between neighboring plants [25]. Ethylene emission, for instance, may induce shade avoidance syndromes such as elongation and narrowing leaf blades [9] [10]. Therefore, chemical communication provides a mechanism that could potentially explain plant genotype-specific responses to neighbors.

In addition to increased plant growth, we observed an increase in reproductive output (fruit set) of receivers in response to indirect exposure to emitter neighbors with a different genotype. It has been shown that the detection of plant competitors can have negative, allelopathic effects on neighbor reproduction [23] [32]. However, a previous study using $A$. thaliana failed to find changes in fruit set as a result of direct competition [33]. In our study, the induction of a competitive-like phenotype showing a higher allocation to growth (taller and larger plants) could account for the unexpected result of increased reproductive output. Upward growth in the monocarpic, basal rosette-forming A. thaliana and other crucifer plants is achieved through increasing inflorescence height [36], which was observed in this study. In fact, a maintenance or increase in fruit production following increased height or branching have been demonstrated in various crucifer species [37] [38] [39]. It could also be speculated that the observed difference in reproductive output of receivers (all Col-0 genotype) could have resulted from differences in the volatile chemicals emitted by each genotype (Col-0 or Ler genotypes); however, this hypothesis was not directly tested in this study. The emitter Ler genotype that induced an increase in receivers' growth is known to constitutively produce specific green leaf volatiles, which is not produced by the Col-0 genotype [27]. Furthermore, green leaf volatiles are known to 
induce the jasmonate pathway [5], which is involved in promoting pollen maturation [40]. Exposure to these green leaf volatiles could potentially increase fecundity and reproductive output of neighboring plants. This hypothesis has not been previously tested and deserves further evaluation.

Even though inflorescence structure (increased branching and height) changed for receivers exposed to undamaged emitters of a different genotype, the proportion of resources allocated above- and below-ground did not differ for any other treatment. Other studies have observed an increase in root growth when competitors are present, even at the cost of reproduction [30]. Additionally, volatile cues of potential competitors have been shown to increase allocation of resources to roots [23]. Using barley plants, a previous study also prevented direct plant interactions, manipulated emitter genotype, and provided adequate resources [23]. However, in contrast to our study, allocation of resources to belowground biomass increased when barley was exposed to volatiles of a different cultivar. Other studies have shown that allocation of resources to roots seems to be dependent on the environmental context such as nutrient, water, and light availability [41] [42]. However, even though the study by Ninkovic [23] and our study provided plants with optimal nutrient environments, results differed in terms of resource allocation towards roots. The discrepancy between these findings could be due to differences in competitive strategies implemented by barley and $A$. thaliana. For instance, barley is known to exude allelopathic chemicals from its roots that inhibit the growth of heterospecific competitors [43] indicating a "competitively confrontational" strategy [44]. Conversely, A. thaliana has been shown to implement both "competitive tolerance" and "competitive confrontational" strategies [45]. In any case, $A$. thaliana is not known for exuding growth inhibiting allelochemicals from its roots. Therefore, the value of allocating biomass to roots for $A$. thaliana under a high nutrient context may be low.

The increased growth and reproductive output of receivers exposed to intact emitters of a different genotype were cancelled when emitter plants were damaged by herbivores. Physiological factors related to anti-herbivore defense could be responsible for the observed context-dependent response. The induction of some defensive pathways, such as the jasmonic acid pathway, has been shown to inhibit cell division, growth, and reproduction in favor of defense when herbivore cues are present [46] [47]. For instance, repeated wounding of $A$. thaliana reduced leaf growth in wild-type plants, but not in mutants with inhibited jasmonic acid synthesis [46]. The study by Yang et al. [47] provided a mechanism for the growth-defense tradeoff in plants in which jasmonic acid (commonly induced by insect herbivory) impedes the gibberellic acid response (a plant hormone involved in plant growth and elongation) via DELLA repressor proteins; thus, implementing a defense rather than growth response. Therefore, defensive cues from damaged emitter plants could be inhibiting an increased growth response in receivers regardless of the genotype of emitters. The suppression of a competitive-like phenotype (taller plants) in response to herbivore-induced volatile cues could suggest a prioritization of defense over growth; 
although, this was not tested in this study. Whereas favoring defense over growth is not usually expected in a highly competitive environment [48], plant-interactions with neighbors in our experiment were indirect. Therefore, we could hypothesize that herbivore-induced plants in the absence of competition could have invested more resources into defense than into growth.

In conclusion, plant genotype and the presence of herbivores on emitter (neighboring) plants influenced responses of $A$. thaliana receiver plants in terms of both growth and reproduction. Studies in a perennial shrub have shown that communication between closely related plants benefits receivers by reducing leaf removal over a growing season [13]. While our study has not explored the subsequent effect of plant-plant communication on herbivory of receiver plants, fitness-related benefits occurred as a result of indirect plant-plant interactions with genetically distinct plants, and only in the absence of herbivores. As such, increased productivity of genetically distinct neighbours suggests a potential advantage of plant-plant volatile communication between genotypes.

\section{Acknowledgements}

We would like to thank the Arabidopsis Biological Resource Center for supplying seeds, and Ryan Walsh for providing feedback on previous versions of this manuscript.

\section{Conflicts of Interest}

The authors declare no conflicts of interest related to the publication of this manuscript.

\section{References}

[1] Stotz, H.U., Pittendrigh, B.R., Kroymann, J., Weniger, K., Fritsche, J., Bauke, A. and Mitchell-Olds, T. (2000) Induced Plant Defense Responses against Chewing Insects. Ethylene Signaling Reduces Resistance of Arabidopsis against Egyptian Cotton Worm But Not Diamondback Moth. Plant Physiology, 124, 1007-1017. https://doi.org/10.1104/pp.124.3.1007

[2] Wittstock, U. and Gershenzon, J. (2002) Constitutive Plant Toxins and Their Role in Defense against Herbivores and Pathogens. Current Opinion in Plant Biology, 5, 300-307. https://doi.org/10.1016/S1369-5266(02)00264-9

[3] McCall, A.C. and Karban, R. (2006) Induced Defense in Nicotiana attenuata (Solanaceae) Fruit and Flowers. Oecologia, 146, 566-571. https://doi.org/10.1007/s00442-005-0284-0

[4] Agrawal, A.A. and Karban, R. (1999) Why Induced Defenses May Be Favored over Constitutive Strategies in Plants. In: Tollrian, R. and Harvell, C.D., Eds., The Ecology and Evolution of Inducible Defenses, Princeton University Press, Princeton, 45-61.

[5] Engelberth, J., Alborn, H.T., Schmelz, E.A. and Tumlinson, J.H. (2004) Airborne Signals Prime Plants against Insect Herbivore Attack. PNAS, 101, 1781-1785. https://doi.org/10.1073/pnas.0308037100

[6] Holopainen, J.K. and Blande, J.D. (2012) Molecular Plant Volatile Communication. 
In: López-Larrea, C., Ed., Sensing in Nature, Springer, New York, 17-31. https://doi.org/10.1007/978-1-4614-1704-0_2

[7] Karban, R., Shiojiri, K., Huntzinger, M. and McCall, A.C. (2006) Damage-Induced Resistance in Sagebrush: Volatiles Are Key to Intra- and Inter-Plant Communication. Ecology, 87, 922-930. https://doi.org/10.1890/0012-9658(2006)87[922:DRISVA]2.0.CO;2

[8] Karban, R., Shiojiri, K. and Ishizaki, S. (2010) An Air Transfer Experiment Confirms the Role of Volatile Cues in Communication between Plants. The American Society of Naturalists, 176, 381-384. https://doi.org/10.1086/655222

[9] Pierik, R., Visser, E.J.W., de Kroon, H. and Voesenek, L.A.C.J. (2003) Ethylene Is Required in Tobacco to Successfully Compete with Proximate Neighbors. Plant, Cell and Environment, 26, 1229-1234. https://doi.org/10.1046/j.1365-3040.2003.01045.x

[10] Pierik, R., Whitelam, G.C., Voesenek, L.A.C.J., de Kroon, H. and Visser, E.J.W. (2004) Canopy Studies on Ethylene-Insensitive Tobacco Identify Ethylene as a Novel Element in Blue Light and Plant-Plant Signaling. The Plant Journal, 38, 310-319. https://doi.org/10.1111/j.1365-313X.2004.02044.x

[11] Seo, S., Sano, H. and Ohashi, Y. (1999) Jasmonate-Based Wound Signal Transduction Requires Activation of WIPK, a Tobacco Mitogen-Activated Protein Kinase. Plant Cell, 11, 289-298. https://doi.org/10.1105/tpc.11.2.289

[12] Karban, R. and Shiojiri, K. (2009) Self-Recognition Affects Plant Communication and Defense. Ecology Letters, 23, 502-506.

https://doi.org/10.1111/j.1461-0248.2009.01313.x

[13] Karban, R., Shiojiri, K., Ishizaki, S., Wetzel, W.C. and Evans, R.Y. (2013) Kin Recognition Affects Plant Communication and Defence. Proceedings of the Royal Society B: Biological Sciences, 280, 201-230. https://doi.org/10.1098/rspb.2012.3062

[14] Karban, R., Wetzel, W.C., Shiojiri, K., Ishizaki, S., Ramirez, S.R. and Blande, J.D. (2014) Deciphering the Language of Plant Communication: Volatile Chemotypes and Sagebrush. New Phytologist, 204, 380-385. https://doi.org/10.1111/nph.12887

[15] Orians, C.M. (2005) Herbivores, Vascular Pathways, and Systemic Induction: Facts and Artifacts. Journal of Chemical Ecology, 31, 2231-2242. https://doi.org/10.1007/s10886-005-7099-7

[16] Davis, M.A., Gordon, M.P. and Smit, B.A. (1991) Assimilate Movement Dictates Remote Sites of Wound-Induced Gene Expression in Poplar Leaves. PNAS, 88, 2393-2396. https://doi.org/10.1073/pnas.88.6.2393

[17] Rhodes, J.D., Thain, J.F. and Wildon, D.C. (1999) Evidence for Physically Distinct Systemic Signaling Pathways in the Wounded Tomato Plant. Annals of Botany, 84,109-116. https://doi.org/10.1006/anbo.1999.0900

[18] Schittko, U. and Baldwin, I.T. (2003) Constraints of Herbivore-Induced Systemic Response: Bidirectional Signaling along Orthostichies in Nicotiana attenuata. Journal of Chemical Ecology, 29, 763-770. https://doi.org/10.1023/A:1022833022672

[19] Frost, C.J., Appel, H.M., Carlson, J.E., De Moraes, C.M., Mescher, M.C. and Schultz, J.C. (2007) Within-Plant Signaling via Volatiles Overcomes Vascular Constraints on Systemic Signaling and Primes Responses against Herbivores. Ecology Letters, 10, 490-498. https://doi.org/10.1111/j.1461-0248.2007.01043.x

[20] Orians, C.M., Pomerleau, J. and Ricco, R. (2000) Vascular Architecture Generates Fine Scale Variation in the Systemic Induction of Proteinase Inhibitors in Tomato. Journal of Chemical Ecology, 26, 471-485. https://doi.org/10.1023/A:1005469724427 
[21] Kiefer, I.W. and Slusarenko, A.J. (2003) The Pattern of Systemic Acquired Resistance Induction within the Arabidopsis Rosette in Relation to the Pattern of Translocation. Plant Physiology, 132, 840-847. https://doi.org/10.1104/pp.103.021709

[22] Karban, R., Baldwin, I.T., Baxter, K.J., Laue, G. and Felton, G.W. (2000) Communication between Plants: Induced Resistance in Wild Tobacco Plants Following Clipping of Neighboring Sagebrush. Oecologia, 125, 66-71. https://doi.org/10.1007/PL00008892

[23] Ninkovic, V. (2003) Volatile Communication between Barley Plants Affects Biomass Allocation. Journal of Experimental Botany, 54, 1931-1939. https://doi.org/10.1093/jxb/erg192

[24] Callaway, R.M. (2002) The Detection of Neighbors by Plants. Trends in Ecology \& Evolution, 17, 104-105. https://doi.org/10.1016/S0169-5347(01)02438-7

[25] Ninkovic, V., Markovic, D. and Dahlin, I. (2016) Decoding Neighbor Volatiles in Preparation for Future Competition and Implications for Tritrophic Interactions. Perspectives in Plant Ecology, Evolution, and Systematics, 23, 11-17. https://doi.org/10.1016/j.ppees.2016.09.005

[26] Kigathi, R.N., Weisser, W.W., Veit, D., Gershezon, J. and Unsicker, S.B. (2013) Plants Suppress Their Emission of Volatiles When Growing with Conspecifics. Journal of Chemical Ecology, 39, 537-545. https://doi.org/10.1007/s10886-013-0275-2

[27] Duan, H., Huang, M.Y., Palacia, K. and Schuler, M.A. (2005) Variations in CYP74B2 (Hydroperoxide Lyase) Gene Expression Differentially Affect Hexenal Signaling in the Columbia and Landsberg Erecta Ecotypes of Arabidopsis. Plant Physiology, 139, 1529-1544. https://doi.org/10.1104/pp.105.067249

[28] Snoeren, T.A., Kappers, I.F., Broekgaarden, C., Mumm, R., Dicke, M. and Bouwmeester, H.J. (2010) Natural Variation in Herbivore-Induced Volatiles in Arabidopsis thaliana. Journal of Experimental Botany, 61, 3041-3056. https://doi.org/10.1093/jxb/erq127

[29] Atkinson, J., Chartier, Y., Pessoa-Silvia, C.L., Jensen, P., Li, Y. and Seto, W.H. (2009) Natural Ventilation for Infection Control in Health-Care Settings. World Health Organization, Geneva. https://www.ncbi.nlm.nih.gov/books/NBK143284

[30] Gersani, M., Brown, J.S., O’Brien, E.E., Maina, G.M. and Abramsky, Z. (2001) Tragedy of the Commons as a Result of Root Competition. Journal of Ecology, 89, 660-669. https://doi.org/10.1046/j.0022-0477.2001.00609.x

[31] Dudley, S.A. and File, A.L. (2007) Kin Recognition in an Annual Plant. Biology Letters, 3, 435-438. https://doi.org/10.1098/rsbl.2007.0232

[32] Keuskamp, D.H., Sasidharan, R. and Pierik, R. (2010) Physiological Regulation and Functional Significance of Shade Avoidance Responses to Neighbors. Plant Signaling \& Behavior, 5, 655-662. https://doi.org/10.4161/psb.5.6.11401

[33] Ballaré, C.L. and Scopel, A.L. (1997) Phytochrome Signaling in Plant Canopies: Testing Its Population-Level Implications with Photoreceptor Mutants of Arabidopsis. Functional Ecology, 11, 441-450. https://doi.org/10.1046/j.1365-2435.1997.00108.x

[34] Bazzaz, F.A., Chiariello, N.R., Coley, P.D. and Pitelka, L.F. (1987) Allocating Resources to Reproduction and Defense. BioScience, 37, 58-67. https://doi.org/10.2307/1310178

[35] Rosenthal, J.P. and Kotanen, P.M. (1994) Terrestrial Plant Tolerance to Herbivory. Trends in Ecology \& Evolution, 9, 145-148. https://doi.org/10.1016/0169-5347(94)90180-5 
[36] Al-Shehbaz, I.A. and O’Kane Jr., S.L. (2002) Taxonomy and Phylogeny of Arabidopsis (Brassicaceae). The Arabidopsis Book, 1, e0001. https://doi.org/10.1199/tab.0001

[37] Benner, B.L. (1988) Effects of Apex Removal and Nutrient Supplementation on Branching and Seed Production in Thlaspi arvense (Brassicaceae). American Journal of Botany, 75, 645-651. https://doi.org/10.1002/j.1537-2197.1988.tb13487.x

[38] Huhta, A.P., Lennartson, T., Tuomi, J., Rautio, P. and Laine, K. (2000) Tolerance of Gentianella campestris in Relation to Damage Intensity: An Interplay between Apical Dominance and Herbivory. Evolutionary Ecology, 14, 373-392. https://doi.org/10.1023/A:1011028722860

[39] Rautio, P., Huhta, A.P., Piippo, S., Tuomi, J., Juenger, T., Saari, M. and Aspi, J. (2005) Overcompensation and Adaptive Plasticity of Apical Dominance in Erysium strictum (Brassicaceae) in Response to Simulated Browsing and Resource Availability. Oikos, 111, 179-191. https://doi.org/10.1111/j.0030-1299.2005.14045.x

[40] Park, J.H., Halitschke, R., Kim, H.B., Baldwin, I.T., Feldmann, K.A. and Feyereisen, R. (2002) A Knock-Out Mutation in Allene Oxide Synthase Results in Male Sterility and Defective Wound Signal Transduction in Arabidopsis Due to a Block in Jasmonic Acid Biosynthesis. The Plant Journal, 31, 1-12.

https://doi.org/10.1046/j.1365-313X.2002.01328.x

[41] Poorter, H. and Nagel, O. (2000) The Role of Biomass Allocation in the Growth Response of Plants to Different Levels of Light, $\mathrm{CO}_{2}$, Nutrients and Water: A Quantitative Review. Australian Journal of Plant Physiology, 27, 597-607. https://doi.org/10.1071/PP99173_CO

[42] Shipley, B. and Meziane, D. (2002) The Balanced-Growth Hypothesis and the Allometry of Leaf and Root Biomass Allocation. Functional Ecology, 16, 326-331. https://doi.org/10.1046/j.1365-2435.2002.00626.x

[43] Liu, D.L. and Lovett, J.V. (1993) Biologically Active Secondary Metabolites of Barley. II. Phytotoxicity of Barley Allelochemicals. Journal of Chemical Ecology, 19, 2231-2244. https://doi.org/10.1007/BF00979660

[44] Novoplansky, A. (2009) Picking Battles Wisely: Plant Behaviour under Competition. Plant, Cell and Environment, 32, 726-741. https://doi.org/10.1111/j.1365-3040.2009.01979.x

[45] Cahill, J.F., Kembel, S.W. and Gustafson, D.J. (2005) Differential Genetic Influences on Competitive Effect and Response in Arabidopsis thaliana. Journal of Ecology, 93, 958-967. https://doi.org/10.1111/j.1365-2745.2005.01013.x

[46] Zhang, Y.I. and Turner, J.G. (2008) Wound-Induced Endogenous Jasmonates Stunt Plant Growth by Inhibiting Mitosis. PLoS ONE, 3, e3699.

https://doi.org/10.1371/journal.pone.0003699

[47] Yang, D.L., Yao, J., Mei, C.S., Tong, X.H., Zeng, L.J., Li, Q., Xiao, L.T., Sun, T.P., Li, J., Deng, X.W. and Lee, C.M. (2012) Plant Hormone Jasmonate Prioritizes Defense over Growth by Interfering with Gibberellin Signaling Cascade. PNAS, 109, E1192-E1200. https://doi.org/10.1073/pnas.1201616109

[48] Rees, M. and Brown, V.K. (1992) Interactions between Invertebrate Herbivores and Plant Competition. Journal of Ecology, 80, 353-360.

https://doi.org/10.2307/2261017 